\title{
Costs and risk factors for ventilator-associated pneumonia in a Turkish University Hospital's Intensive Care Unit: A case-control study
}

\author{
Riza Hakan Erbay*1, Ata Nevzat Yalcin², Mehmet Zencir ${ }^{3}$, Simay Serin ${ }^{1}$ and \\ Habip Atalay ${ }^{1}$
}

Address: ${ }^{1}$ Department of Anaesthesiology and Reanimation, Medicine Faculty, Pamukkale University, Denizli, Turkey, ${ }^{2}$ Department of Infectious Diseases and Clinical Microbiology, Medicine Faculty, Akdeniz University, Antalya, Turkey and ${ }^{3}$ Department of Public Health, Medicine Faculty, Pamukkale University, Denizli, Turkey

Email: Riza Hakan Erbay* - rherbay@pamukkale.edu.tr; Ata Nevzat Yalcin - anyalcin@yahoo.com;

Mehmet Zencir - mzencir@pamukkale.edu.tr; Simay Serin - sserin@pamukkale.edu.tr; Habip Atalay - hatalay@pamukkale.edu.tr

* Corresponding author

Published: 26 April 2004

BMC Pulmonary Medicine 2004, 4:3
Received: 06 February 2004

Accepted: 26 April 2004

This article is available from: http://www.biomedcentral.com/I47I-2466/4/3

(c) 2004 Erbay et al; licensee BioMed Central Ltd. This is an Open Access article: verbatim copying and redistribution of this article are permitted in all media for any purpose, provided this notice is preserved along with the article's original URL.

\begin{abstract}
Background: Ventilator-associated pneumonia (VAP) which is an important part of all nosocomial infections in intensive care unit (ICU) is a serious illness with substantial morbidity and mortality, and increases costs of hospital care. We aimed to evaluate costs and risk factors for VAP in adult ICU.
\end{abstract}

Methods: This is a-three year retrospective case-control study. The data were collected between OI January 2000 and 3 I December 2002. During the study period, I 32 patients were diagnosed as nosocomial pneumonia of 73I adult medical-surgical ICU patients. Of these only 37 VAP patients were assessed, and multiple nosocomially infected patients were excluded from the study. Sixty non-infected ICU patients were chosen as control patients.

Results: Median length of stay in ICU in patients with VAP and without were 8.0 (IQR: 6.5) and 2.5 (IQR: 2.0) days respectively ( $\mathrm{P}<0.000 \mathrm{I}$ ). Respiratory failure (OR, II.8; 95\%, Cl, 2.2-62.5; $\mathrm{P}<$ 0.004), coma in admission (Glasgow coma scale < 9) (OR, I7.2; 95\% Cl, 2.7-107.7; $\mathrm{P}<0.002$ ), depressed consciousness (OR, 8.8; 95\% Cl, 2.9-62.5; $\mathrm{P}<0.02$ ), enteral feeding (OR, 5.3; $95 \% \mathrm{Cl}$, I.0-27.3; $\mathrm{P}=0.044)$ and length of stay $(\mathrm{OR}, \mathrm{I} .3 ; 95 \% \mathrm{Cl}, \mathrm{I} .0-\mathrm{I} .7 ; \mathrm{P}<0.04)$ were found as important risk factors. Most commonly isolated microorganism was methicillin resistant Staphylococcus aureus $(30.4 \%)$. Mortality rates were higher in patients with VAP $(70.3 \%)$ than the control patients (35.5\%) $(P<0.003)$. Mean cost of patients with and without VAP were $2832.2+/-1329.0$ and $868.5+$ / -428.0 US Dollars respectively $(P<0.0001)$.

Conclusion: Respiratory failure, coma, depressed consciousness, enteral feeding and length of stay are independent risk factors for developing VAP. The cost of VAP is approximately five-fold higher than non-infected patients. 


\section{Background}

Nosocomial pneumonia (NP) which is an important part of all nosocomial infections in intensive care unit (ICU) is a serious illness with substantial morbidity and mortality, and increases costs of hospital care [1-3]. The term of nosocomial pneumonia (hospital-acquired pneumonia) broadly covers all infections occurring after the first 48 hours of the hospital admission excluding any infection incubations in this period. Intensive care unit acquired pneumonia (occurring after the first 48 hours of admission to the ICU) and ventilator-associated pneumonia (VAP; occurring after the first 48 hours of starting mechanical ventilation) are also included in the broader term "nosocomial pneumonia" [4]. Risk factors for VAP include mechanical ventilation for $>48$ hours, stay in an ICU, duration of ICU or hospital stay, severity of underlying illness, and presence of co morbidities. Pseudomonas aeruginosa, Staphylococcus aureus, and Enterobacter are the most common causes of NP [5]. The greatest number of reports on NP in ICUs is published from USA, and reports from Turkey are scarce. The importance of international comparisons of results of infection surveillance data for prevention of nosocomial infection and reaching a quality of care is stressed [6]. This is the first cost analysis and risk factor study on VAP in ICU from a developing country, Turkey.

\section{Methods}

This retrospective case control study was performed between 01 January 2000 and 31 December 2002 in the Anaesthesiology Intensive Care Unit in Pamukkale University Hospital, Denizli, Turkey.

The three years data collected in this study consisted of 97 (37 intubated patients with VAP and 60 controls) adult ICU patients. Multiple nosocomial infections including pneumonia and NP in non-intubated patients were excluded from the study because we aimed to detect independent risk factors and the costs, for only VAP. Sixty mechanically ventilated control cases that stayed in the ICU for more than 48 hours and did not develop any nosocomial infection were chosen with respect to similarity of age (+/- 2 years), gender, and underlying disease with the VAP group.

The central medical-surgical adult ICU was a six-bed unit staffed by four physicians and twelve nurses. Haematological and biochemical tests (daily), chest radiographs (2-4 times in a week) and microbiological cultures from blood, nasopharynx, tracheal aspirate, urine and wounds (on admission and twice a week) were performed routinely. An infectious diseases physician consultated the patients daily. An infection control nurse collected data daily on standard surveillance charts. The decision of VAP or colonisation was made according to the laboratory and clini- cal findings. Appropriate antimicrobial therapy was given to the patients when necessary. Education on infection control procedures is performed twice in a year for all ICU staff. Infection control measures and guidelines on prevention of nosocomial infections are applied according to CDC [7].

All data including gender, age, admission and discharge date, admission diagnosis and the Acute Physiology and Chronic Health Evaluation II (APACHE II) score at patient's admission to the ICU were recorded. The other data consisting of the usage of $\mathrm{H}_{2}$ receptor antagonist, mechanical ventilation, nasogastric tubing, blood transfusion, central venous catheterisation, urinary catheterisation, tracheotomy, surgical drains, malignancy, trauma, diabetes mellitus, renal failure (serum-creatinine $\geq 200$ $\mathrm{mol} / \mathrm{l})$, respiratory failure $\left(\mathrm{PaCO}_{2}>49 \mathrm{~mm} \mathrm{Hg}\right.$ and/or $\mathrm{PaO}_{2}<50-60 \mathrm{mmHg}$ ), central nervous system disease, coma (GCS = Glasgow coma scale < 9), depressed consciousness, intoxication, surgical operations, infection on admission, infection sites, isolated microorganisms and their susceptibility patterns and mortality were also recorded. All these factors were investigated as possible risk factors for VAP.

Criteria for defining VAP were those recommended by the CDC [7]. A diagnosis of VAP was considered when radiological evidence of new and persistent ( $>48 \mathrm{hrs}$ ) pulmonary infiltrates were detected together with at least two of the following features: temperature higher than $38^{\circ} \mathrm{C}$ and lower than $35^{\circ} \mathrm{C}$, peripheral leukocytosis, $\left(5000\right.$ per $\mathrm{mm}^{3}$ or a $25 \%$ increase in the circulating leukocytes from baseline), or leukocyte recount lower than 4000 per $\mathrm{mm}^{3}$ purulent respiratory secretions, and appearance or worsening of respiratory insufficiency. Moreover, the presence of significant growth on quantitative cultures of the bronchoscopic protected specimen brush $\left(\geq 10^{3}\right.$ colony forming units $(\mathrm{cfu}) / \mathrm{ml}$ ) was required to accept the pneumonia as microbiologically proven [8]. Patients were followed daily until discharge from the ICU or to death. Risk of mortality for each group based on their APACHE II scores was analysed.

\section{Statistical analysis}

Statistical analysis was performed in two steps using SPSS 10.0 (SPSS Inc., Chicago, USA). First, categorical variables such as possible risk factors for VAP were assessed with bivariate analyses (Pearson correlation). Second, all of the risk factors, which were found significant with bivariate analysis, were included in a model, and multivariate logistic regression analysis was done. All $P$-value less than 0.05 were considered significant. 
Table I: Characteristics and admission diagnosis of patients

\begin{tabular}{|c|c|c|c|}
\hline & VAP Group $(n=37)$ & Control Group $(n=60)$ & $P$ - value \\
\hline Characteristic & median (IQR) & median (IQR) & \\
\hline Age (years) & $56.0(25.0)$ & $56.5(14.8)$ & NS \\
\hline APACHE II score & $23.0(7.0)$ & $14.0(10.0)$ & $<0.0001$ \\
\hline Length of stay in ICU (days) & $8.0(6.5)$ & $2.5(2.0)$ & $<0.0001$ \\
\hline Admission diagnosis & No of patients (\%) & No of patients (\%) & \\
\hline Trauma & $8(21.6 \%)$ & $7(11.7 \%)$ & \\
\hline Pulmonary disease & 7 (18.9\%) & $9(15.0 \%)$ & \\
\hline CNS disease & 7 (18.9\%) & $8(13.3 \%)$ & \\
\hline Renal insufficiency & $2(5.4 \%)$ & $5(8.3 \%)$ & \\
\hline CVS disease & $3(8.1 \%)$ & $6(10.0 \%)$ & \\
\hline Infectious disease & $3(8.1 \%)$ & $2(3.3 \%)$ & \\
\hline Intoxication & $3(8.1 \%)$ & $6(10.0 \%)$ & \\
\hline Malignancy & I (2.7 \%) & 7 ( $11.7 \%)$ & \\
\hline Others & $3(8.1 \%)$ & $10(16.7 \%)$ & \\
\hline
\end{tabular}

Values are expressed as median, IQR (Interquartile Range). Abbreviations: VAP: ventilator-associated pneumonia; APACHE II score: the Acute Physiology and Chronic Health Evaluation II score, NS: non-significant, CNS: central nervous system, CVS: cardiovascular system.

Table 2: Bivariate and multivariate analyses of risk factors for VAP (mean \pm SD)

\begin{tabular}{|c|c|c|c|c|c|c|}
\hline \multirow[b]{2}{*}{ Risk factors } & \multirow[b]{2}{*}{ VAP Group } & \multirow[b]{2}{*}{ Control Group } & \multicolumn{2}{|c|}{ Bivariate analysis } & \multicolumn{2}{|c|}{ Multivariate analysis } \\
\hline & & & OR $(95 \% \mathrm{Cl})$ & P-value & OR $(95 \% \mathrm{Cl})$ & P-value \\
\hline Respiratory failure & 34 (91.9 \%) & $12(20.0 \%)$ & $\begin{array}{c}45.3(11.8- \\
173.0)\end{array}$ & $<0.0001$ & $11.8(2.2-62.5)$ & 0.004 \\
\hline Coma $(\mathrm{GCS}<9)$ & $23(62.2 \%)$ & $3(5.0 \%)$ & $31.2(8.2-118.9)$ & $<0.0001$ & $17.2(2.7-107.7)$ & 0.002 \\
\hline Depressed consciousness & $25(67.6 \%)$ & $12(20.0 \%)$ & $29.4(10.9-58.7)$ & $<0.0001$ & $8.8(2.9-62.5)$ & 0.02 \\
\hline Enteral feeding & $30(81.1 \%)$ & $14(23.3 \%)$ & $14.1(5.1-38.9)$ & $<0.0001$ & $5.3(1.0-27.3)$ & 0.044 \\
\hline Length of stay & $9.4 \pm 7.1$ & $3.5 \pm 2.3$ & & $<0.0001$ & $1.3(1.0-1.7)$ & 0.023 \\
\hline APACHE II scores & $22.9 \pm 5.2$ & $15.3 \pm 7.0$ & & $<0.0001$ & -- & NS \\
\hline Nasogastric tubing & $28(75.7 \%)$ & $21(35.0 \%)$ & $5.8(2.3-14.5)$ & 0.001 & -- & NS \\
\hline CVC & $32(86.5 \%)$ & $41(68.3 \%)$ & 3.0 I.0-7.3) & 0.044 & -- & NS \\
\hline Diabetes mellitus & $5(13.5 \%)$ & $2(3.3 \%)$ & $4.5(0.8-24.7)$ & NS & & \\
\hline Trauma & I (2.7\%) & $2(3.3 \%)$ & $0.8(0.1-9.2)$ & NS & & \\
\hline Blood transfusion & $14(37.8 \%)$ & $21(35.0 \%)$ & I.I (0.4-2.6) & NS & & \\
\hline TPN & $9(24.3 \%)$ & $15(25.0 \%)$ & $1.0(0.4-2.5)$ & NS & & \\
\hline Corticosteroids & $2(5.4 \%)$ & $5(8.3 \%)$ & $0.6(0.1-3.4)$ & NS & & \\
\hline $\mathrm{H}_{2}$ receptor antagonists & $37(100.0 \%)$ & $58(96.7 \%)$ & - & NS & & \\
\hline Urinary catheterization & $37(100.0 \%)$ & $57(95.0 \%)$ & -- & NS & & \\
\hline PVC & $30(81.1 \%)$ & $45(75.0 \%)$ & $1.4(0.6-3.9)$ & NS & & \\
\hline Surgical drains & $8(21.6 \%)$ & $11(18.3 \%)$ & $1.2(0.4-3.4)$ & NS & & \\
\hline Tracheostomy & $2(5.4 \%)$ & I (I.7\%) & $3.3(0.3-38.6)$ & NS & & \\
\hline Arterial cannulation & $3(8.1 \%)$ & -- & -- & NS & & \\
\hline
\end{tabular}

Values are expressed as mean \pm SD and number of patients (\%). Possible risk factors for VAP were assessed with bivariate analysis. All of the risk factors which were found significant with bivariate analysis were included in a model, and multiple logistic regression analysis was done. Abbreviations: OR: odds ratio, Cl: confidence interval, PVC: peripheral venous catheter, CVC: central venous catheterization, TPN: total parenteral nutrition.

\section{Results}

From a total of 731 ICU patients 132 of them were diagnosed as NP during the study period. Of these only 37 intubated patients with VAP were included in the study. Multiple nosocomial infections including pneumonia (n $=92)$ or non-intubated patients with NP $(n=3)$ were excluded from the study. The ages of the patients were between 20 and 74 (Table 1). The incidence rate of VAP was 8.9 in 1000-patient days. The duration of ventilation before diagnosis of VAP was found as 4.0 days. 
Table 3: Costs of therapeutic interventions in the ICU (US Dollars)

\begin{tabular}{|c|c|c|c|c|c|}
\hline & \multicolumn{2}{|c|}{ VAP group $(n=37)$} & \multicolumn{2}{|c|}{ Control group $(n=60)$} & \multirow[b]{2}{*}{ P-value } \\
\hline & Median(IQR) & Mean ( $\pm S D)$ & Median (IQR) & Mean ( $\pm S D)$ & \\
\hline ICU bed cost & $190.8(166.4)$ & $230.2 \pm 120.2$ & $92.4(78.6)$ & $113.5 \pm 72.2$ & $<0.0001$ \\
\hline Antibiotics & $589.6(378.3)$ & $576.7 \pm 362.4$ & $98.9(141.1)$ & $219.2 \pm 458.2$ & $<0.002$ \\
\hline Laboratory & $400.6(264.5)$ & $435.0 \pm 273.4$ & $106.8(127.3)$ & $112 \pm 134.2$ & $<0.0001$ \\
\hline Other drugs & $218.3(587.8)$ & $497.4 \pm 553.5$ & I 35.8 (229.5) & $204.3 \pm 288.4$ & 0.032 \\
\hline Mechanical ventilation & $90.8(68.5)$ & $108.9 \pm 51.2$ & 0.0 & $11.9 \pm 23.6$ & $<0.0001$ \\
\hline Respiratory circuit. filters & $60.5(36.6)$ & $59.7 \pm 36.4$ & 0.0 & $10.7 \pm 21.5$ & $<0.0001$ \\
\hline Tracheal aspiration & $298.9(146.8)$ & $321.9 \pm 159.8$ & 0.0 & $21.7 \pm 40.8$ & $<0.0001$ \\
\hline IV infusion sets & $84.6(64.1)$ & $97.3 \pm 37.9$ & $33.7(13.5)$ & $40.2 \pm 23.7$ & $<0.0001$ \\
\hline CVC & $26.1(0.4)$ & $29.9 \pm 11.6$ & $26.1(0.0)$ & $21.3 \pm 11.3$ & 0.021 \\
\hline Enteral nutritional products & II3.I (163.7) & $137.3 \pm 211.5$ & $0.0(0.0)$ & $13.0 \pm 37.4$ & 0.002 \\
\hline Parenteral nutritional products & $0.0(82.2)$ & $76.1 \pm 111.5$ & $0.0(0.0)$ & $12.9 \pm 42.2$ & 0.008 \\
\hline Urinary catheters & $5.3(1.4)$ & $6.4 \pm 3.4$ & $5.3(0.0)$ & $5.0 \pm 1.5$ & 0.028 \\
\hline Monitorization & II $4.8(81.5)$ & $131.3 \pm 54.6$ & $32.6(32.6)$ & $49.9 \pm 27.4$ & $<0.0001$ \\
\hline Wound dressing & $26.6(23.2)$ & $38.8 \pm 17.5$ & $9.3(7.1)$ & $11.6 \pm 8.4$ & $<0.0001$ \\
\hline Blood transfusion & $0.0(116.3)$ & $90.3 \pm 177.1$ & $0.0(0.0)$ & $21.3 \pm 51.9$ & 0.038 \\
\hline Total & $2839.3(1585.6)$ & $2832.2 \pm 1329.0$ & $653.4(825.2)$ & $868.5 \pm 428.0$ & $<0.0001$ \\
\hline
\end{tabular}

Values are expressed as median, IQR (interquartile range) and mean \pm SD (standard deviation).

Table 4: Mortality rates based on APACHE II scores

\begin{tabular}{|c|c|c|c|c|c|c|}
\hline & \multirow[b]{2}{*}{ Death } & \multirow[b]{2}{*}{ Discharged } & \multicolumn{2}{|c|}{ Bivariate analysis } & \multicolumn{2}{|c|}{ Multivariate analysis } \\
\hline & & & OR $(95 \% \mathrm{Cl})$ & $P$-value & OR $(95 \% \mathrm{Cl})$ & P-value \\
\hline VAP Group & $26(70.3)$ & II (29.7) & $4.4(1.8-10.6)$ & 0.002 & -- & NS \\
\hline Control Group & $21(35.0)$ & $39(65.0)$ & -- & & -- & NS \\
\hline \multicolumn{7}{|l|}{ APACHE II } \\
\hline$<10$ & $3(13.0)$ & $20(87.0)$ & -- & $<0.0001$ & -- & \\
\hline $11-20$ & $15(40.5)$ & $22(59.5)$ & $4.5(1.1-18.0)$ & & $4.5(1.1-18.0)$ & 0.032 \\
\hline$>20$ & $29(78.4)$ & $8(21.6)$ & $24.1(5.7-102.3)$ & & $24.1(5.7-102.3)$ & $<0.0001$ \\
\hline Total & $47(48.5)$ & $50(51.5)$ & & & & \\
\hline
\end{tabular}

Admission diagnoses of the patients, information regarding the length of stay in ICU and APACHE II scores are shown in Table 1. Significant possible risk factors for VAP are shown in Table 2. Multiple logistic regression analysis revealed that respiratory failure, coma in admission (Glasgow coma scale < 9), depressed consciousness, enteral feeding and length of stay were significant risk factors for VAP in ICU with (Table 2).

The most frequently isolated microorganisms were methicillin resistant Staphylococcus aureus (30.4\%), Pseudomonas aeruginosa (21.4\%), Acinetobacter spp. (12.5\%) and Klebsiella pneumoniae (10.7\%). In early onset pneumonias MRSA, MR-KNS, E. coli and K. pneumoniae, in late onset pneumonias $P$. aeruginosa, Acinetobacter spp. and MRSA were the predominant isolated pathogens in this study. Early onset pneumonia was described as pneumonia occurring in the first three to five days after admission to the hospital.
Median costs of patients with VAP and without VAP were 2839.3 (IQR: 1585.6) and 653.4 (IQR: 825.2) US Dollars respectively $(P<0.0001)$. Distribution of costs is shown in Table 3.

Crude mortality rates were higher in patients with VAP $(70.3 \%)$ than the control patients $(35.0 \%)(P<0.002)$. Mortality rate due to organ failures was found as $46.2 \%$. Mortality for each group based on their APACHE II scores is shown in Table 4.

\section{Discussion}

Although patients in ICU are a small subgroup of all hospitalised patients they account for approximately $25 \%$ of all nosocomial infections. The incidence of nosocomial infections in ICU is high due to underlying disease, severity of illness, type of ICU, length of stay and invasive devices used. Nosocomial pneumonia is the leading cause of death from hospital-acquired infections $[9,10]$. 
In our ICU, NP was the most common nosocomial infection [11] similar to the published studies from other countries $[1,3,12,13]$. The estimated prevalence of NP within the hospital settings ranges from $10 \%$ to $65 \%$, with case fatality rates which is greater than $25 \%$ in most studies [14]. The incidence of VAP in ICU which are reported as $15.5 \%$ [15] and $9.3 \%$ [16].

Recent investigations also suggest that NP has become the most common nosocomial infection among critically ill patients $[1,17]$. Despite abundant literature on the management of NP, a number of aspects, from diagnosis to the therapy, are still controversial [18].

Respiratory failure, length of stay, coma (GCS < 9) in admission, depressed consciousness, enteral feeding and length of stay were found significant independent risk factors by using multivariate analysis in our patients with VAP. Although risk factors for the development of NP in ICU patients have been assessed in multiple studies, results are frequently controversial mainly due to methodological differences. However, mechanical ventilation, $\mathrm{H}_{2}$ receptor blocker usage, prophylactic antimicrobial therapy, depressed consciousness, massive gastric aspiration [19-23], length of stay in ICU, duration of mechanical ventilation, trauma, severity of illness and underlying disease, male gender $[16,24]$, transfer from another hospital ward, a colonized central venous catheter [25], unplanned extubation, reintubation after weaning [26], supine body position, enteral nutrition, Glasgow coma scale score of less than $9[8]$ are reported as independent risk factors for developing NP in ICU patients. Our results are generally in accordance with these studies but we did not find $\mathrm{H}_{2}$ receptor blockers as independent risk factor for NP. This might be due to almost all the patients received the drugs for stress ulcer prophylaxis.

In this study, the most frequently isolated microorganisms were methicillin resistant Staphylococcus aureus (30.4\%), Pseudomonas aeruginosa $(21.4 \%)$ and Acinetobacter spp. $(12.5 \%)$. This is in accordance with different studies where Staphylococcus aureus, Pseudomonas aeruginosa, Acinetobacter spp. and Enterobacter spp. were isolated from ICU patients with NP $[14,19,28,29]$.

In our study, crude mortality rates were higher in patients with VAP $(70.3 \%)$ compared to control patients (35.5\%). The risk of death based on three scale APACHE II scores was calculated in two groups. APACHE II scores and VAP contribute the mortality in bivariate analysis but in multivariate analysis only APACHE II scores were significant (Table 4). Tejada Artigas et al. [19] found the mortality rates for patients with and without NP were $43.5 \%$ and $18.8 \%$ respectively. Georges et al. [30] reported that the mortality rate increased from $33.3 \%$ to $54.3 \%$ after diag- nosis of NP in their patients. Different methodologies including case control or cohort studies with multivariate analysis were used in order to determine mortality rate of NP. Whatever the method used, results are very heterogeneous and highly controversial. Even if the methodology of those studies is most often appropriate, results remain extremely confusing and raise more questions than provide answers. For example, the mortality rates of control patients range from $5 \%$ to $39 \%$, and the mortality rates of patients with VAP range from $24 \%$ to $58 \%$ in the studies. Thus, the attributable mortality is influenced by the global strategy used to diagnose and manage NP, which varies considerably from one country to another [31,32].

Extra costs of nosocomial infections include; bed, ICU stay, haematological, biochemical, microbiological and radiological tests, antibiotics, other drugs, extra surgical procedures and working hours. Drug and especially antibiotic acquisition in addition to increased length of stay are the widely used and well-described parameters in calculating cost. Litigation, mortality and morbidity and some other parameters are not very well described in calculating costs in nosocomial infections $[33,34]$. Therefore the impact of mortality on the calculations of cost is difficult to interpret. Ventilator-associated pneumonia adds significant costs to individual hospitalisations. Centres for Disease Control [35] estimated that an episode of NP added 5.9 days to the average hospital stay and $\$ 5683$ in excess costs. Other estimates put the excess hospital costs associated with NP at $\$ 4947$ per episode of NP [36]. Boyce and colleagues [37] also reported that, among 31 of 33 Medicare patients who developed NP, hospital costs for the entire admission exceeded reimbursements, with a net loss of $\$ 5800$ per case. Dietrich et al. [38] reported an excess cost amounted to 14606 DM in patients with NP. Warren et al. [15] reported that patients with VAP had significantly higher hospital costs than uninfected patients ( $\$ 70,568$ vs. $\$ 21,620)$, and estimated the attributable cost of VAP to be $\$ 11,897)$. Total ICU expenditure was $\$ 2832.2 \pm 1329.0$ USD for VAP group and $\$ 868.5 \pm 428.0$ for the control group in our study.

Economic analysis of patients with VAP in ICU showed that a group of invasive devices and procedures including central venous catheters, respiratory circuit and filters, urinary catheters, intravenous infusion catheters, enteral or parenteral nutritional products, aspiration and monitorization is accounted the most important part of the cost followed by antibiotics and laboratory investigations (Table 3). In the assessment of costs, our results are consistent with a marked excess cost of VAP, but when compared with the other studies from Europe and North America our ICU bed prices and procedure costs are lower in our country [35-38]. Besides, as a developing country in Turkey, extremely low fee of ICU bed and procedures [39], 
the magnitude of the hospital may affect the costs from the point of realized medical processes. We think that the most important data is the cost of VAP, and it is approximately five-fold higher than control patients.

In conclusion, respiratory failure, coma (GCS $<9$ ) in admission, depressed consciousness, enteral feeding and length of stay are independent risk factors for developing VAP in our ICU. High mortality rates and costs of VAP suggest that infection control activities which are aimed to prevent VAP in ICU must be constantly maintained in order to improve the quality of care.

\section{References}

I. Vincent JL, Bihari DJ, Suter PM, Bruining HA, White J, Nicolas-Chanoin $M H$, Wolff $M$, Spencer RC, Hemmer M: The prevalence of nosocomial infection in intensive care units in Europe. Results of the European Prevalence of Infection in Intensive Care (EPIC) Study. EPIC International Advisory Committee. JAMA 1995, 274:639-644.

2. Legras A, Malvy D, Quinioux AI, Villers D, Bouachour G, Robert R, Thomas R: Nosocomial infections: prospective survey of incidence in five French intensive care units. Intensive Care Med 1998, 24: 1040-1046.

3. Ponce de Leon-Rosales SP, Molinar-Ramos F, Dominguez-Cherit G, Rangel-Frausto MS, Vazquez-Ramos VG: Prevalence of infections in intensive care units in Mexico: a multicenter study. Crit Care Med 2000, 28:|3|6-|32|.

4. Vincent JL: Prevention of nosocomial bacterial pneumonia. Thorax 1999, 54:544-549.

5. Lynch JP: Hospital-acquired pneumonia-risk factors, microbiology, and treatment. Chest 200I, I I 9:S373-S384.

6. Mertens R, Van den Berg JM, Veerman-Brenzikofer ML, Kurz X, Jans $B$, Klazinga $N$ : International comparison of results of infection surveillance: The Netherlands versus Belgium. Infect Control Hosp Epidemiol 1994, I 5:574-578.

7. Garner JS, Jarvis WR, Emori TG, Horan TC, Hughes JM: CDC definitions for nosocomial infections, 1988. Am J Infect Control 1988, 16:128- 140 .

8. Fagon JY, Chastre J, Domart Y, Trouillet JL, Pierre J, Darne C, Gibert $\mathrm{C}$ : Nosocomial pneumonia in patients receiving continuous mechanical ventilation. Prospective analysis of 52 episodes with use of a protected specimen brush and quantitative culture techniques. Am Rev Respir Dis 1989, 139:877-884.

9. Trilla A: Epidemiology of nosocomial infections in adult intensive care units. Intensive Care Med 1994, 20(Suppl 3):SI-4.

10. Eggimann P, Pittet D: Infection control in the ICU. Chest 200I, 1 20:2059-2093.

II. Erbay H, Yalcin AN, Serin S, Turgut H, Tomatir E, Cetin B, Zencir M: Nosocomial infections in intensive care unit in a Turkish university hospital: a 2-year survey. Intensive Care Med 2003, 29:1482-1488

12. Richards MJ, Edwards JR, Culver DH, Gaynes RP: Nosocomial infections in combined medical-surgical intensive care units in the United States. Infect Control Hosp Epidemiol 2000, 21:510-515.

13. Richards MJ, Edwards JR, Culver DH, Gaynes RP: Nosocomial infections in medical intensive care units in the United States. National Nosocomial Infections Surveillance System. Crit Care Med 1999, 27:887-892.

14. Kollef $\mathrm{MH}$ : Epidemiology and risk factors for nosocomial pneumonia. Emphasis on prevention. Clin Chest Med 1999, 20:653-670

15. Warren DK, Shukla SJ, Olsen MA, Kollef MH, Hollenbeak CS, Cox MJ Cohen MM, Fraser V]: Outcome and attributable cost of ventilator-associated pneumonia among intensive care unit patients in a suburban medical center. Crit Care Med 2003, 31:1312-1317.

16. Rello J, Ollendorf DA, Oster G, Vera-Llonch M, Bellm L, Redman R, Kollef MH: VAP Outcomes Scientific Advisory Group. Epide- miology and outcomes of ventilator-associated pneumonia in a large US database. Chest 2002, I 22:2II5-2I II.

17. Kollef MH, Sharpless L, Vlasnik J, Pasque C, Murphy D, Fraser VJ: The impact of nosocomial infections on patient outcomes following cardiac surgery. Chest 1997, I I 2:666-675.

18. Mehta RM, Niederman MS: Nosocomial pneumonia. Curr Opin Infect Dis 2002, 15:387-394.

19. Tejada Artigas A, Bello Dronda S, Chacon Valles E, Munoz Marco J, Villuendas Uson MC, Figueras P, Suarez FJ, Hernandez A: Risk factors for nosocomial pneumonia in critically ill trauma patients. Crit Care Med 200I, 29:304-309.

20. Harris JR, Joshi M, Morton PG, Soeken KL: Risk factors for nosocomial pneumonia in critically ill trauma patients. AACN Clin Issues 2000, I I:| |98-23I.

21. Antonelli M, Moro ML, Capelli O, De Blasi RA, D'Errico RR, Conti G, Bufi M, Gasparetto A: Risk factors for early onset pneumonia in trauma patients. Chest 1994, 105:224-228.

22. Kampf G, Wischnewski N, Schulgen G, Schumacher M, Daschner F: Prevalence and risk factors for nosocomial lower respiratory tract infections in German hospitals. J Clin Epidemiol 1998, $51: 495-502$

23. Craven DE, Steger KA: Epidemiology of nosocomial pneumonia. New perspectives on an old disease. Chest 1995, I08(2 Suppl): IS-16S.

24. Vincent JL, Lobo S, Struelens M: Ventilator associated pneumonia: risk factors and preventive measures. J Chemother 200I, 13:21|-217.

25. Vanhems P, Lepape A, Savey A, Jambou P, Fabry J: Nosocomial pulmonary infection by antimicrobial-resistant bacteria of patients hospitalised in intensive care units: risk factors and survival. J Hosp Infect 2000, 45:98-106.

26. de Lassence A, Alberti C, Azoulay E, Le Miere E, Cheval C, Vincent F Cohen Y, Garrouste-Orgeas M, Adrie C, Troche G, Timsit JF, OUTCOMEREA Study Group: Impact of unplanned extubation and reintubation after weaning on nosocomial pneumonia risk in the intensive care unit: a prospective multicenter study. Anesthesiology 2002, 97: | 48-156.

27. Drakulovic MB, Torres A, Bauer TT, Nicolas JM, Nogue S, Ferrer M: Supine body position as a risk factor for nosocomial pneumonia in mechanically ventilated patients: a randomised trial. Lancet 1999, 27(354): | $85 \mid-1858$.

28. Torres A, El-Ebiary M, Rano A: Respiratory infectious complications in the intensive care unit. Clin Chest Med 1999, 20:287-30I.

29. Akca O, Koltka K, Uzel S, Cakar N, Pembeci K, Sayan MA, Tutuncu AS, Karakas SE, Calangu S, Ozkan T, Esen F, Telci L, Sessler DI, Akpir $\mathrm{K}$ : Risk factors for early-onset, ventilator-associated pneumonia in critical care patients: selected multiresistant versus nonresistant bacteria. Anesthesiology 2000, 93:638-645.

30. Georges H, Leroy O, Guery B, Alfandari S, Beaucaire G: Predisposing factors for nosocomial pneumonia in patients receiving mechanical ventilation and requiring tracheotomy. Chest 2000, I I 8:767-774.

31. Dalton HJ: Dying from or with a nosocomial pneumonia in the intensive care unit? Crit Care Med 200I, 29:2392-2394.

32. Bercault N, Boulain T: Mortality rate attributable to ventilatorassociated nosocomial pneumonia in an adult intensive care unit: a prospective case-control study. Crit Care Med 200I, 29:2303-2309.

33. Wilcox MH, Dave J: The cost of hospital-acquired infection and the value of infection control. J Hosp Infect 2000, 45:8I-84.

34. Yalcin AN: Socioeconomic burden of nosocomial infections. Indian J Med Sci 2003, 57:450-456.

35. Public health focus: Surveillance, prevention, and control of nosocomial infections. MMWR Morb Mortal Wkly Rep 1992, 41:783-787.

36. Jarvis WR: Selected aspects of the socioeconomic impact of nosocomial infections: Morbidity, mortality, cost, and prevention. Infect Control Hosp Epidemiol 1996, 17:552-557.

37. Boyce JM, Potter-Bynoe G, Dziobek L, Solomon SL: Nosocomial pneumonia in Medicare patients. Hospital costs and reimbursement patterns under the prospective payment system. Arch Intern Med 1991, 151:1109-1 I I4.

38. Dietrich ES, Demmler M, Schulgen G, Fekec K, Mast O, Pelz K, Daschner FD: Nosocomial pneumonia: a cost-of-illness analysis. Infection 2002, 30:61-67. 
39. Yalcin AN, Hayran M, Unal S: Economic analysis of nosocomial infections in a Turkish University Hospital. J Chemother 1997, $9: 4||-4 \mid 4$.

\section{Pre-publication history}

The pre-publication history for this paper can be accessed here:

http://www.biomedcentral.com/1471-2466/4/3/prepub

Publish with Bio Med Central and every scientist can read your work free of charge

"BioMed Central will be the most significant development for disseminating the results of biomedical research in our lifetime. " Sir Paul Nurse, Cancer Research UK

Your research papers will be:

- available free of charge to the entire biomedical community

- peer reviewed and published immediately upon acceptance

- cited in PubMed and archived on PubMed Central

- yours - you keep the copyright 